\title{
Diabetes mellitus - a challenging metabolic disorder of the modern world
}

\author{
Nabeela $^{1}$, Khaliq Ur Rahman ${ }^{2}$, Saadat Mehmood ${ }^{1}$ and Muhammad $^{3 *}$ \\ 1. Centre of Biotechnology and Microbiology, University of Peshawar, KP-Pakistan \\ 2. Department of Chemistry, University of Swabi, KP-Pakistan \\ 3. Department of Microbiology, University of Swabi, KP-Pakistan \\ *Corresponding author's email: muhammad@uoswabi.edu.pk \\ Citation \\ Nabeela, Khaliq Ur Rahman, Saadat Mehmood and Muhammad. Diabetes mellitus - a challenging metabolic \\ disorder of the modern world. Pure and Applied Biology. Vol. 8, Issue 2, pp1684-1689. \\ http://dx.doi.org/10.19045/bspab.2019.80111
}

Received: 26/02/2019

Revised: $17 / 06 / 2019$

Accepted: $24 / 06 / 2019$

Online First: 28/06/2019

\section{Abstract}

The current review focused on Diabetes mellitus (DM), a Non-communicable disease (NCDs) which is the prominent cause of death. Diabetes mellitus has mainly two types, Type 1 diabetes mellitus is known as IDDM while Type 2 diabetes mellitus is known as NIDDM. About 5-10\% of the diabetes patients have identified type 1 while $90-95 \%$ of the diabetes patients have identified type 2. Diabetes mellitus are the $4^{\text {th }}$ death causing disease, having 1.5 million motility rates annually. Diabetes is the main public health challenge in developed and developing countries that comprised in non-transmissible diseases. It is associated with other maladies like Obesity, Heart Failure, Obstructive Sleep Apnoea, Behaviour changes, and Depression which may lead to death. Depression is one of the foremost imperative community fitness problems that are regularly comorbid with diabetes. It has been concluded that people suffering from diabetes have major effect on their existences, nutrition, physical and mental activity.

Keywords: Diabetes mellitus; Metabolic disorder; Modern world

\section{Introduction}

Non-communicable diseases (NCDs) are the leading cause of death. Annual deaths rate is 3.8 billion round the world. The four main non-communicable diseases are accounting for $82 \%$ of all NCD deaths including Diabetes, Cardiovascular diseases, chronic respiratory diseases and cancer [1]. Mortality rate is almost $80 \%$ in low and middle-income countries due to NCD [2]. Predominantly in Pakistan, non-communicable diseases are one of the reasons of morbidity and mortality [3]. NCDs are cause for $50 \%$ of total demises in Pakistan and probability of declining from age of 30- 70 years, due to four major NCDs is $26 \%$ rendering WHO country profile [4].
Amongst NCDs, diabetes mellitus (DM) is ranked $4^{\text {th }}$ affecting deaths calculating for 1.5 million worldwide annually losses. Worldwide, in 2014 diabetes occurrence was 9\% among adults [5]. According to International Diabetes Federation [IDF] across the world 382 million people aging between 40 and 59 years are currently living with diabetes and expected $55 \%$ will increase in the year 2035. At present 175 million people with diabetes are undiagnosed [6].

Diabetes Mellitus (DM) is a prolong metabolic disease caused by decrease in insulin secretion or functions leading to hyperglycaemia. The resulting hyperglycaemia may lead to acute metabolic 
complications including ketoacidosis and chronic micro-vascular complications. It starts from 3 years in children and 25 years in adults. Type 1 is categorized by a lack of insulin production while Type 2 diabetes is caused by insulin receptor dysfunctions and ineffective use of insulin. It frequently results from excess body weight and physical inactivity.

\section{Type 1 diabetes}

Type 1 diabetes known as IDDM. About 5$10 \%$ of patients have diabetes type 1 . Insufficient amount of insulin produces by pancreases, results in need of insulin injection to control blood glucose. Type 1 mostly occurred in young people and generally caused by an immune related devastation of insulin producing pancreatic beta cell results in insulin deficiency.

\section{Type 2 diabetes}

Type 2 diabetes identified as NIDDM about 90-95\% patients have type 2 diabetes [7]. It results from reduction in amount of insulin production. Type 2 diabetes is metabolic disorder classified by insulin resistance and dysfunctional of pancreatic beta cell [8]. The occurrences of type 2 diabetes rising considerably [9]. Type 2 diabetes defined according to epidemiologic circumstances, treatment by means of diet, with or without exercise of oral antihyperglycemic agents, or by treatment with insulin, applied to only patients who were 40 years or older at time of diabetes diagnose [10].

\section{Disorders}

Diabetes diseases have main public health challenges in developed and non-developing countries that comprised in non-transmissible diseases. As results of their outcome on personal and national health that liable for mortality and morbidity. Occurrence of diabetes worldwide in all age groups extended $2.8 \%$ for 2000 and expected to be $4.4 \%$ in 2030 with increase in number of people affected by diabetes. Worldwide about $90 \%$ cases labelled with type 2 diabetes. In Pakistan occurrence of diabetes is high ranging from 7.6 to $11 \%$ [11].

\section{Obesity}

Type 2 diabetes mainly endemic because of increase in obesity in younger age group. Obesity is a main threat factor for the development of type 2 diabetes mellitus, there is increasing evidence that overweight or obese patients with type 2 diabetes mellitus experience lower mortality compared with patients of normal weight [12, 13]. The main reason of obesity is taking diet containing high calorie and lack of exercise plays an important role in dysfunction of insulin receptor leading to diabetes [14].

\section{Heart failure}

Researcher investigates longstanding inclinations in all causes mortality and frequency of major diabetes related cardiovascular obstacles, as related with current trends in general population. Heart failure has deserted complications of diabetes. The coexistence of type 2 diabetes mellitus (T2DM) and heart failure (HF), either with reduced (HFrEF) or preserved ejection fraction $(\mathrm{HFpEF})$, is frequent $(30-$ $40 \%$ of patients) and associated with a higher risk of $\mathrm{HF}$ hospitalization, all-cause and cardiovascular (CV) mortality. The most important causes of $\mathrm{HF}$ in $\mathrm{T} 2 \mathrm{DM}$ are coronary artery disease, arterial hypertension and a direct detrimental effect of T2DM on the myocardium [15].

\section{Cardiovascular possibility features}

Type 2 diabetes mellitus associated with many difficulties containing macro angiopathy and main risk factors for coronary disease $[16,17]$. The mortality in patients T2DM doubled while mortality interrelated to cardiovascular disease increased contrast to that of non-diabetic patients [18]. It has expected by end of 2030 T2DM diagnosed in 552 million people worldwide that shows growing severity of health problem [19]. 


\section{Obstructive sleep apnoea}

Patients with type 2 diabetes mellitus suffering from many obstacles among them are obstructive sleep apnoea (OSA) [21, 22]. Increased in risk of cardiovascular disease obstructive sleep apnoea is associated [23]. In adding OSA associated with daytime sleepiness, mood changes, and cerebral dysfunction [24]. All condition ruins patient ability to increase their helper levels and change their important lifestyle. Some agents found that sleepiness is daily burden in patients with T2DM and least number of activities performed during daytime [25].These activities involve helper thus obstructive sleep apnoea and extreme daytime sleepiness in people with T2DM have negative effects [26]. In 2014, Chein found reduced strength in diaphragm in people without T2DM when related with matched control [27]. Type 2 diabetes reduced inspiratory muscle result of catabolic factors related with T2DM.Catabolic effect on muscle induced by complication comprising neuropathy, insulin resistance and chronic inflammation. So reduce inspiratory strength and muscle diaphragm effect by diabetic obstacle [28].

\section{Behaviour changes}

Behaviour defined as manner that one performs action or reaction of person in response to internal or external motivation. Behaviour modification due to people suffering from diabetes that indication to changes in their lifestyle. Present study reports manners deviations of diabetic patient with respect to their group surroundings and to their disease [29].

\section{Renal impairment}

Decrease renal function results as changes in glycaemia level in diabetic patients whom metformin discontinued. Once Egfr decrease up to $30 \mathrm{ml} / \mathrm{min} / 1.73 \mathrm{~m}^{2}$ and to decreae metaformin dose in mild temperate renal impairment [30-32]. Vitamins D through regulation of calcium, effect several mechanisms interconnected to pathphysiology of T2DM, having pancreatic $\beta$ cell function failure and reduced insulin production [33, 34]. Based on longitudinal pancreatic $\beta$ cell observational studies, recommended that improving vitamin $D$ level decrease insulin conflict, improve glycaemic level control and reduce risk of type 2 diabetes $[35,36]$. Results from underpowered trials on effects of vitamin D supplementation on glycemic results have unpredictable [37, 38]. Deficiency of vitamin D is called nonclassical cardiovascular risk factor [39].

\section{Depression}

Depression is one of the foremost imperative community fitness problems that are regularly comorbid with diabetes [40]. About their disease, diabetic patients become anxious and regarding social and professional impact of diabetes [41]. It stated that their relationship between depression and existence of type 2 diabetes with insignificant relation between diabetes and risk of depression [39]. Diabetes diagnosis main factor to limit effect of disease upon individuals' life styles [42]. Death rate in patients with T2DM doubled while death rate associated to cardiovascular disease triple in contrast to that of non-diabetic patients [43]. It is expected that end of 2030 T2DM have diagnosed in 552 million people worldwide shows growing gravity of this health problem [44].

\section{Conclusion}

It is concluded that people suffering from diabetes have major effect on their lifestyles, diet, physical activity but also change behaviour and attitudes to daily life style having job desire, social and married life. It caused serious control on person living that effect their surroundings.

\section{Authors' contributions}

Conceived and designed the experiments: Muhammad, Performed the experiments: Nabeela, Analyzed the data: S Mehmood, 
Contributed reagents/ materials/ analysis tools: KU Rahman, wrote the paper: Nabeela.

\section{References}

1. World Health Organization. Noncommunicable diseases. Fact sheet. Updated January (2015). Available from URL: http://www.who.int/ media Centre/factsheets/fs355/en/

2. World Health Organization. 10 facts on non-communicable diseases. (updated March 2013). [Cited on January 31, 2015]. Available from URL: http://www.who.int/ features/fact files/non-communicable diseases/en/

3. Jafar TH, Haaland BA, Rahman A, Razzak JA, Bilger M \& Naghavi M (2013). Non-communicable diseases and injuries in Pakistan: strategic priorities. Lancet 381(9885): 2281-90.

4. World Health Organization Noncommunicable Diseases (NCD) Country Profiles, 2014. [Cited on January 22, 2015]. Available from URL: http://www.who.int/nmh/ countries/pak_en.pdf

5. Global status report on noncommunicable diseases 2014. Geneva, World Health Organization. [Cited on January 31, 2015]. Available from URL: http://www. who.int/globalcoordination-mechanism/ publications/global-status-report-ncds2014-eng.pdf

6. International Diabetes Federation. IDF Diabetes Atlas. Sixth Edition (2013). [Cited on January 22, 2015.] Available from URL: http://www.idf.org/diabetesatlas

7. Bluestone JA, Herold K \& Eisenbarth $G$ (2010). Genetics, pathogenesis and clinical interventions in type 1 diabetes. Nature 464: 1293-300.

8. Kahn SE, Cooper ME \& Del Prato S (2014). Pathophysiology and treatment of type 2 diabetes: perspectives on the past, present, and future. Lancet 383: 1068-83.

9. Whiting DR, Guariguata L, Weil C \& Shaw J (2011). IDF diabetes atlas: global estimates of the prevalence of diabetes for 2011 and 2030. Diabetes Res Clin Pract 94: 311-21.

10. Boyle JP, Thompson TJ, Gregg EW, Barker LE \& Williamson DF (2010). Projection of the year 2050 burden of diabetes in the US adult population: dynamic modeling of incidence, mortality, and prediabetes prevalence. Popul Health Metr 8: 29.

11. Piemonte L. 5th Edition of the Diabetes Atlas released on World Diabetes Day. IDF Diabetes Atlas, 2011.

12. Jin SH, Edward J \& Boyko (2018). The Evidence for an Obesity Paradox in Type 2 Diabetes Mellitus. Diabetes Metab J 42: 179-187.

13. Alison JP, Amelia CC, Amberbir A \& Kayuni-Chihana N (2019). Prevalence of obesity, hypertension, and diabetes, and cascade of care in sub-Saharan Africa: a cross-sectional, population-based study in rural and urban Malawi. Lancet Diabetes Endocrinol S2213-8587: (17)30432-1.

14. Gove ME \& Fantuzzi G (2010). Adipokines, Nutrition, and Obesity. In: Adrianne Bendich RJD, editor. Preventive nutrition. 4th ed: Humana Press, pp 419-32.

15. Petar MS, Petrie SMC, Filippatos SG, Anker SD \& Rosano G (2018).Type 2 diabetes mellitus and heart failure: a position statement from the Heart Failure Association of the European Society of Cardiology. European J of Heart Failure doi:10.1002/ejhf.1170.

16. Storgaard H, Mortensen B, Almdal T, Laub M \& Tarnow L (2014). At least one in three people with type 2 diabetes mellitus referred to a diabetes centre has symptomatic obstructive sleep apnoea," 
Diabetic Medicine: $A J$ of the British Diabetic Association 31: 1460-1467.

17. Brissac RB, Phirai S \& Larifla L (2015). Hypertension and cardiovascular risk associated with obstructive sleep apnea in adult in Guadeloupe (French West Indies). Annales de Cardiologie et d'Angeiologie 64: 132-138.

18. Sanchez AI, Martinez P, Miro E, Bardwell WA \& Buela-Casal G (2009). "CPAP and behavioral therapies in patients with obstructive sleep apnea: effects on daytime sleepiness, mood, and cognitive function. Sleep Medi Reviews 13: 223-233.

19. Chasens ER \& Olshansky E (2006). The experience of being sleepy while managing type 2 diabetes. $J$ of the American Psychiatric Nurses Assoc 12: 272-278.

20. Chien MY, Wu YT, Lee PL, Chang YJ \& Yang PC (2010). Inspiratory muscle dysfunction in patients with severe obstructive sleep apnoea. The European Resp J 35: 373-380.

21. Vranish JR \& Bailey EF (2016). Inspiratory muscle training improves sleep and mitigates cardiovascular dysfunction in obstructive sleep apnea. Sleep 39: 1179-1185.

22. Siwasaranond N, Nimitphong $H$, Manodpitipong A, Saetung S, Chirakalwasan $\mathrm{N}$ \& Thakkinstian A (2018).The Relationship between Diabetes-Related Complications and Obstructive Sleep Apnea in Type 2 Diabetes. $J$ of Diabetes Res https://doi.org/10.1155/2018/9269170.

23. Ajzen I \& Cote NG (2008). Attitudes and the Prediction of Behaviour. In: D CW, Radmila P, editors. Attitudes and Attitude Change. Frontiers of Social Psychology. New York: Psychol Press: 289-311.

24. Mitri J,. Muraru MD \& Pittas AG (2011). Vitamin D and type 2 diabetes: a systematic review. European J of Clini Nutri 65: 1005-1015.

25. Takiishi T, Gysemans C, Bouillon R \& Mathieu C (2010). Vitamin D and diabetes. Endocrinol Metabol Clinics of North America 39: 419-446.

26. Pittas AG, Sun Q, Manson JE, DawsonHughes B \& Hu FB (2010). Plasma 25hydroxyvitamin $\mathrm{D}$ concentration and risk of incident type 2 diabetes in women. Diabetes Care 33: 2021-2023.

27. Pittas A, Lau J, Hu F \& Dawson-Hughes B (2009). The role of vitamin D and calcium in type 2 diabetes. A systematic review and meta-analysis. The J of Clini Endocrinol and Metabol 92: 2017-2029.

28. Liu E, Meigs JB \& Pittas AG (2010). Predicted 25- hydroxyvitamin D score and incident type 2 diabetes in the Framingham Offspring Study. American J of Clini Nutri 91: 1627-1633.

29. Grimnes G, Emaus N \& Joakimsen RM (2010). Baseline serum 25hydroxyvitamin D concentrations in the Troms $\emptyset$ Study 1994-95 and risk of developing type 2 diabetes mellitus during 11 years of follow-up. Diabetic Med 27: 1107-1115.

30. Gagnon C, Lu ZX \& Magliano DJ (2011). Serum 25- hydroxyvitamin D, calcium intake, and risk of type 2 diabetes after 5 years: results from a national, population-based prospective study (the Australian Diabetes, Obesity and Lifestyle study). Diabetes Care 34: 1133-1138.

31. Mitri J, Dawson-Hughes B, Hu F \& Pittas A (2011). Effects of vitamin D and calcium supplementation on pancreatic $\beta$ cell function, insulin sensitivity, and glycemia in adults at high risk of diabetes: the Calcium and Vitamin D for Diabetes Mellitus (CaDDM) randomized controlled trial. American J of Clin Nutri 94: 486-494. 
32. Xuan Y, Zhao HY \& Liu JM (2013). Vitamin D and type 2 diabetes mellitus (D2). J of Diabetes 5: 261-267.

33. Wolden-Kirk H, Overbergh L, Christesen HT, Brusgaard K \& Mathieu C (2011).Vitamin D and diabetes: its importance for beta cell and immune function. Mol and Cellular Endocrinol 347: 106-120.

34. Talaei A, Mohamadi M \& Adgi Z (2013). The effect of vitamin D on insulin resistance in patients with type 2 diabetes. Diabetol \& Metabolic Syndrome 5: 8.

35. I. Athanassiou $\mathrm{K}$, Athanassiou $\mathrm{P}$, Gkountouvas A \& Kaldrymides P (2013). Vitamin D and glycemic control in diabetes mellitus type 2. Therapeutic Adv in Endocrinol and Metabol 4: 122128.

36. Angellotti E \& Pittas A.G (2017). The role of vitamin $\mathrm{D}$ in the prevention of type 2 diabetes: to $\mathrm{D}$ or not to $\mathrm{D}$. Endocrinol 158: 2013-2021.

37. Jorde R \& Figenschau Y (2009). Supplementation with cholecalciferol does not improve glycaemic control in diabetic subjects with normal serum 25hydroxyvitamin D levels. European J of Nutri 48: 349-354.

38. Parekh D, Sarathi V, Menon PS \& Shah NS (2010). Pilot study to evaluate the effect of short-term improvement in vitamin D status on glucose tolerance in patients with type 2 diabetes mellitus. Endocrine Practice 16: 600-608.

39. Michos ED \& Melamed ML (2008). Vitamin D and cardiovascular disease risk. Curr Opinion in Clinical Nutri and Metabol Care 11: 7-12,

40. Mulugeta HT, Dessie GA, Wagnew FS (2018). The Prevalence of Depression among Diabetic Patients in Ethiopia: A Systematic Review and Meta-Analysis, 2018. Depression Research and Treatment, https://doi.org/10.1155/2018/6135460.

41. Speight J, Reaney MD \& Barnard KD (2009). Not all roads lead to Rome-a review of quality of life measurement in adults with diabetes. The Auth $J$ Compilation 26: 315-27.

42. Mezuk B, Eaton WW, Albrecht S \& Golden SH (2008). Depression and type 2 diabetes over the lifespan: a metaanalysis. Diabetes Care 31: 2383-90

43. Hydrie M, Shera A, Fawwad A, Basit A $\&$ Hussain A (2009). Prevalence of metabolic syndrome in urban Pakistan (Karachi): comparison of newly proposed International Diabetes Federation and modified Adult Treatment Panel III criteria. Metab Syndr Relat Disord 7: 119-24.

44. Fox CS (2010). Cardiovascular disease risk factors, type 2 diabetes mellitus, and the Framingham Heart Study. Trends in Cardiovascular Med 20: 90-95. 